\title{
Transformation of iodide and formation of iodinated by-products in heat activated persulfate oxidation process
}

\author{
Lu Wang ${ }^{\mathrm{a}}$, Deyang Kong ${ }^{\mathrm{b}}$, Yuefei $\mathrm{Ji}^{\mathrm{a}}$, Junhe $\mathrm{Lu}^{\mathrm{a}^{*}}$, Xiaoming Yin ${ }^{\mathrm{a}}$, Quansuo Zhou ${ }^{\mathrm{a}}$ \\ ${ }^{a}$ Department of Environmental Science and Engineering, Nanjing Agricultural University, \\ Nanjing, 210095, China \\ ${ }^{\mathrm{b}}$ Nanjing Institute of Environmental Science, Ministry of Environmental Protection of PRC, \\ Nanjing, 210042, China
}

*Corresponding author: E-mail: jhlu@ njau.edu.cn;

Telephone: (86) 25-84395164; Fax: (86) 25-84395210 


\begin{abstract}
Formation of halogenated disinfection by-products (DBPs) in sulfate radical-based advanced oxidation processes (SR-AOPs) have attracted considerable concerns recently. Previous studies have focused on the formation of chlorinated and brominated DBPs. This research examined the transformation of $\mathrm{I}^{-}$in heat activated PS oxidation process. Phenol was employed as a model compound to mimic the reactivity of dissolved natural organic matter (NOM) toward halogenation. It was found that $\mathrm{I}^{-}$was transformed to free iodine which attacked phenol subsequently leading to iodinated DBPs such as iodoform and iodoacetic acids. Iodophenols were detected as the intermediates during the formation of the iodoform and triiodoacetic acid (TIAA). However, diiodoacetic acid (DIAA) was formed almost concomitantly with iodophenols. In addition, the yield of DIAA was significantly higher than that of TIAA, which is distinct from conventional halogenation process. Both the facts suggest that different pathway might be involved during DIAA formation in SR-AOPs. Temperature and persulfate dose were the key factors governing the transformation process. The iodinated by-products can be further degraded by excessive $\mathrm{SO}_{4}{ }^{-}$and transformed to iodate. This study elucidated the transformation pathway of $\mathrm{I}^{-}$in SR-AOPs, which should be taken into consideration when persulfate was applied in environmental matrices containing iodine.
\end{abstract}

Keywords: Sulfate radical; Iodide; Iodinated disinfection by-products; Iodophenols; Reaction pathway 


\section{Introduction}

Sulfate radical $\left(\mathrm{SO}_{4}{ }^{-}\right)$is a single electron oxidant with a redox potential of $2.5-3.1 \mathrm{~V}$ (depending on $\mathrm{pH})$ comparable to that of hydroxyl radical $(\mathrm{OH} \bullet, 2.7 \mathrm{~V}$ in acid solution and $1.8 \mathrm{~V}$ in neutral solution) (Buxton et al., 1988). $\mathrm{SO}_{4}{ }^{-}$-based advanced oxidation processes (SR-AOPs) have been demonstrated as viable approaches to degrade a variety of organic pollutants (Pera-Titus et al., 2004, Shen et al., 2008, Zhang et al., 2014). $\mathrm{SO}_{4}{ }^{-}$can be generated via decomposition of peroxymonosulfate (PMS) (Anipsitakis and Dionysiou, 2003) or persulfate (PS) (Adewuyi and Sakyi, 2013) by heat, UV, transient metals, and base etc. (Tsitonaki et al., 2010, Guan et al., 2011, Hu and Long, 2016, Oh et al., 2016) Compared with $\mathrm{H}_{2} \mathrm{O}_{2}$ and $\mathrm{O}_{3}$, which serve as the precursors of $\mathrm{OH} \bullet$ in conventional AOPs, PS and PMS are more stable and soluble (Ali et al., 2014). This offers great advantage and flexibility in the application of SR-AOPs at various scenarios. Due to these advantages, SR-AOPs have attracted increasing attention in soil/groundwater remediation (Zeng et al., 2015).

Like $\mathrm{OH} \bullet, \mathrm{SO}_{4}{ }^{-}$can react with various water constituents such as natural organic matter (NOM), carbonate, halides, etc., resulting in reduced treatment efficiency of targeted contaminants (Magazinovic et al., 2004, Bennedsen et al., 2012, Adewuyi and Sakyi, 2014). However, $\mathrm{OH} \bullet$ and $\mathrm{SO}_{4}{ }^{--}$show distinct selectivity toward these non-targeted water constituents (Yang et al., 2014). $\mathrm{OH} \bullet$ is more likely being scavenged by $\mathrm{NOM}$ than $\mathrm{SO}_{4}{ }^{--}$. A recent study showed that $75 \%$ of the $\mathrm{OH} \bullet$ was consumed by $\mathrm{NOM}$ in $\mathrm{UV} / \mathrm{H}_{2} \mathrm{O}_{2}$ process for membrane brine treatment, while halides and carbonate scavenging was less important in this system (Yang et al., 2016). Scavenging of $\mathrm{OH} \bullet$ by NOM showed adverse effects on the degradation of contaminants. In contrast, $\mathrm{SO}_{4}{ }^{--}$is less likely to react with $\mathrm{NOM}$ while halides become the dominant radical scavengers in UV/PS system. In spite of this, the treatment efficiency of targeted organic contaminants was only slightly affected (Yang et al., 2016). Reactions between $\mathrm{SO}_{4}{ }^{--}$and halides generate halogen radical species $\left(\mathrm{X}^{\bullet}, \mathrm{X}_{2}{ }^{-}\right)$and free halogens $\left(\mathrm{HXO}, \mathrm{X}_{2}\right)(\mathrm{R} 1-6)$ (Fang and Shang, 
2012, Lu et al., 2015). Both of them are highly reactive, especially to electron-rich compounds (Hasegawa and Neta, 1978, Yang et al., 2014). As a result, the formation of reactive halogen species compensated the loss of $\mathrm{SO}_{4}{ }^{-}$due to halides scavenging.

$$
\begin{aligned}
& \mathrm{SO}_{4}^{--}+\mathrm{X}^{-} \rightarrow \mathrm{X} \cdot+\mathrm{SO}_{4}^{2-} \\
& \mathrm{X}_{2}^{--}+\mathrm{X} \cdot \rightarrow \mathrm{X}_{2}+\mathrm{X}^{-} \\
& \mathrm{X} \cdot+\mathrm{X}^{-} \rightarrow \mathrm{X}_{2}^{-} \\
& \mathrm{X}_{2}^{--}+\mathrm{X}_{2}^{--} \rightarrow \mathrm{X}_{2}+2 \mathrm{X} \\
& \mathrm{X} \cdot+^{-} \cdot \rightarrow \mathrm{X}_{2} \\
& \mathrm{X}_{2}+\mathrm{H}_{2} \mathrm{O} \leftrightarrow \mathrm{HXO}+\mathrm{H}^{+}+\mathrm{X}^{-}
\end{aligned}
$$

Although the degradation of organic contaminants was little affected by halides in SR-AOPs, concerns still exist because the reactions of reactive halogen species with organic contaminants may lead to the formation of halogenated by-products. Among all halide species, reactions of $\mathrm{Br}^{-}$ in SR-AOPs were most extensively studied (Fang and Shang, 2012, Wang et al., 2014, Lutze et al., 2014, Lu et al., 2015, Liu et al., 2015, Lu et al., 2016, Ji et al., 2016, Xie et al., 2016). It was reported that $\mathrm{SO}_{4}{ }^{--}$could oxidize $\mathrm{Br}^{-}$to form carcinogenic bromate $\left(\mathrm{BrO}_{3}{ }^{-}\right)$, during which $\mathrm{HBrO}$ was the key intermediate. $\mathrm{HBrO}$ could react with $\mathrm{NOM}$, if presented, resulting in reduced formation of $\mathrm{BrO}_{3}{ }^{-}$(Fang and Shang, 2012). More recently, we demonstrated that such reactions between $\mathrm{HBrO}$ and $\mathrm{NOM}$ could lead to the formation of bromated by-products such as bromoform and bromoacetic acids (Lu et al., 2015). These compounds are known as disinfection by-products (DBPs) because they are ubiquitously formed during water disinfection processes. However, these brominated DBPs (Br-DBPs) can be degraded by $\mathrm{SO}_{4}{ }^{--}$and release $\mathrm{Br}^{-}$again. As such, partial $\mathrm{Br}^{-}$could be cycled for multiple times between organic and inorganic forms in 
SR-AOPs. With excessive $\mathrm{SO}_{4}{ }^{--}$, all $\mathrm{Br}^{-}$will be converted to $\mathrm{BrO}_{3}{ }^{-}$ultimately; otherwise, a fraction of $\mathrm{Br}^{-}$will be in form of organic bromine (Liu et al., 2015, Lu et al., 2015). Similar formation of Br-DBPs was also found in the degradation of tetrabromobisphenol A (TBBPA) by $\mathrm{SO}_{4}{ }^{--}$in the absence of inorganic $\mathrm{Br}^{-}(\mathrm{Ji}$ et al., 2016). In this case, the bromine in the brominated by-products was originated from TBBPA per se. During this process, the bromine probably underwent transformation from organic to inorganic and to organic again.

$\mathrm{Cl}^{-}\left(\mathrm{Cl} \cdot / \mathrm{Cl}^{-}, 2.41 \mathrm{~V}\right)$ can also be oxidized by $\mathrm{SO}_{4}{ }^{--}$to form reactive chlorine species that leads to the chlorinated by-products (Huie et al., 1991). It was found that presence of $\mathrm{Cl}^{-}$resulted in the increased absorbable organic halogen (AOX) during the degradation of trichlorophenol in $\mathrm{Co}^{2+} / \mathrm{PMS}$ system (Fang et al., 2016). Anipsitakis et al. (2006) reported the formation of tetrachloride during the degradation of phenolic compounds by $\mathrm{SO}_{4}{ }^{-}$in the presence of $\mathrm{Cl}^{-}$. Xie et al. (2016) found that chlorinated DBPs could be formed in $\mathrm{Co}^{2+} / \mathrm{PMS}$ system in the presence of both $\mathrm{Br}^{-}$and $\mathrm{Cl}^{-}$.

$\mathrm{I}^{-}$has a reduction potential of $1.33 \mathrm{~V}$ (Yeo and Choi, 2009). In principle, it is more readily oxidized than $\mathrm{Cl}^{-}\left(\mathrm{Cl} / \mathrm{Cl}^{-}, 2.41 \mathrm{~V}\right)$ and $\mathrm{Br}^{-}\left(\mathrm{Br}^{\circ} / \mathrm{Br}^{-}, 1.62 \mathrm{~V}\right)$ (Huie et al., 1991). Presumably, it can be oxidized and transformed by $\mathrm{SO}_{4}{ }^{-}$just as $\mathrm{Cl}^{-}$and $\mathrm{Br}^{-}$. Upon oxidation, $\mathrm{I}^{-}$will be transformed to a series of reactive iodine species (RIS) including radical iodines $\left(\mathrm{I}^{\circ}, \mathrm{I}_{2}{ }^{--}\right)$and free iodine (R1-6). RIS can react with NOM, generating iodinated DBPs (I-DBPs) such as iodoform and iodoacetic acids (IAAs). I-DBPs can cause taste and odor issues. The organoleptic threshold concentration of iodoform lies between 0.03 and $1 \mu \mathrm{g} / \mathrm{L}$, which is the lowest among all of the iodo-trihalomethanes (Khiari, 2002). In addition, mammalian cell assays revealed that I-DBPs were more cytotoxic and/or genotoxic than their chlorinated and brominated analogs. For instance, iodoform was 60 times and 146 times more cytotoxic than bromoform and chloroform, respectively (Ye et al., 2012). Cytoxicity of diiodoacetic acid (DIAA) is approximately 2 and 34 folder higher than that of dibromoacetic acid (DBAA) and dichloracetic acid (DCAA), 
respectively (Khiari, 2002, Plewa et al., 2002). Therefore, formation of I-DBPs has caused increasing concerns in water treatment, although their yields are significantly less than that of Cl-DBPs and Br-DBPs (Plewa, 2004, Richardson et al., 2008, Ding and Zhang, 2009, Plewa and Wagner, 2009, Ye et al., 2013, Liu et al., 2014).

Formation of I-DBPs in SR-AOPs has be demonstrated in several researches recently. Chu et al. (2016) reported the formation of iodinated di-haloacetamides during PS oxidation in the presence of $\mathrm{Br}^{-}$and $\mathrm{I}^{-}$. More recently, formation of iodoform and IAAs were demonstrated in carbon nanotube activated PS oxidation system in the presence of $\mathrm{I}^{-}$and NOM (Guan et al., 2017). In addition, Li et al. (2017) found that PMS without activators was capable to oxidize $\mathrm{I}^{-}$to free iodine and lead to I-DBPs subsequently. All these studies used NOM as the substrate for the formation of I-DBPs. Although such an approach has the advantage of realism, it does not yield structure-specified mechanisms of the iodination process. To address this challenge, transformation of $\mathrm{I}^{-}$in the presence of phenol as the substrate in heat/PS system were examined in an attempt to elucidate the pathways of iodine incorporation into the organic molecules and the I-DBPs generation. We employed phenol as a model compound of NOM because it is widely recognized that the phenolic moieties in NOM molecules serve as the principal reactive sites for free halogen attack in water chlorination (Bichsel and Gunten, 2000, Lu et al., 2004). We believe the results of this study are complementary to the aforementioned studies and helps to develop a better understanding of the transformation of $\mathrm{I}^{-}$in SR-AOPs.

\section{Materials and methods}

\subsection{Reagents and materials}

All chemicals were of at least analytical grade. Phenol, PS, KI, and $\mathrm{N}, \mathrm{N}$-dimethyl-1,4-phenylenediamine monohydrochloride (DPD) were purchased from Aladdin (Shanghai, China). 2-Iodophenol (98\%), 4-iodophenol (99\%) and monoiodoacetic acid (MIAA) (98\%) were purchased form Sigma-Aldrich (USA). 2,4,6-Triiodophenol (98\%) was purchased 
from TCI (Japan). Iodoform (99.5\%) was purchased from Xiya Reagent (Chengdu, China). DIAA (90\%) and triiodoacetic acid (TIAA) (90\%) was obtained from Toronto Research Chemicals Inc. (Canada). HPLC grade methyl tert-butyl ether (MTBE), methanol, acetonitrile and acetic acid were purchased from Burdich \& Jackson (Shanghai, China). Stock solutions of phenol, PS, and KI were prepared by dissolving appropriate amount of the reagents in Milli-Q water (18.2 $\mathrm{M} \Omega \cdot \mathrm{cm})$.

\subsection{Batch reaction setup}

I-DBPs formation were examined in a series of 42-mL EPA vials with headspace free. Samples containing $0.05 \mathrm{mM} \mathrm{I}^{-}, 0.05 \mathrm{mM}$ phenol, and $10 \mathrm{mM}$ phosphate buffer $(\mathrm{pH} 7)$ were pre-heated to the working temperature in a water bath before PS was dosed. Since only a tiny amount of PS stock solution was added, the changes caused with regard to the volume and temperature of the reaction solutions were negligible. The vials were immersed in a water bath during the reaction. At preset time, 2 vials were withdrawn (for iodoform and IAAs each) and chilled in an ice bath to quench the reactions. Preliminary experiments have demonstrated that a rapid decrease of temperature could effectively cease the reactions caused by PS (Lu et al., 2015). Temperature of $40,50,60^{\circ} \mathrm{C}$ and PS doses of $0.5,1.0,2.0,5.0 \mathrm{mM}$ were tested.

\subsection{Analysis of DBPs}

Methods for quantifying iodoform and IAAs were similar to that of US EPA Standard Method 551.1 and 552.2 (Munch and Hautman, 1995; Hodgeson et al., 1995), respectively. The analytes were concentrated by liquid-liquid extraction using MTBE. Iodoform was analyzed by an Agilent 7890 gas chromatograph (GC) equipped with an electron capture detector (ECD) and HP-5 fused silica capillary column $(30 \mathrm{~m} \times 0.53 \mathrm{~mm}$ i.d., $1.5 \mathrm{~m}$ film thickness $)$. The temperature program used to separate the analyses was as follows: initially held at $50^{\circ} \mathrm{C}$ for $1 \mathrm{~min}$, increased at $10^{\circ} \mathrm{C} / \mathrm{min}$ to $150^{\circ} \mathrm{C}$, held for an additional $8 \mathrm{~min}$, then increased at $20^{\circ} \mathrm{C} / \mathrm{min}$ to $200^{\circ} \mathrm{C}$ and held for $5 \mathrm{~min}$. The temperature of the injector and detector were 200 and $260^{\circ} \mathrm{C}$, respectively. The 
detection limit was $0.06 \mu \mathrm{g} / \mathrm{L}$. IAAs were analyzed by GC-ECD with the same capillary column after samples being methylated with $10 \%$ sulfuric acid in methanol. The temperature program was as follows: initial temperature of $50^{\circ} \mathrm{C}$ held for $8 \mathrm{~min}$, then increased at $5^{\circ} \mathrm{C} / \mathrm{min}$ to $150^{\circ} \mathrm{C}$, followed by increasing to $200^{\circ} \mathrm{C}$ at $10^{\circ} \mathrm{C} / \mathrm{min}$ and held for additional $3 \mathrm{~min}$. The detection limits of IAAs varied from $0.06-0.25 \mu \mathrm{g} / \mathrm{L}$. Samples for IAAs analysis were methylated within $4 \mathrm{~h}$ after reaction to avoid any decomposition of analytes (Chen, 2011). All the experiments were carried out in triplicates, and the data were averaged. The standard deviations were usually within 5-10\% unless otherwise stated.

\subsection{Analysis of free iodine and iodate}

Formation of free iodine was investigated at the same conditions as described in DBPs study. An aliquot of $1 \mathrm{~mL}$ sample was taken from the reaction solution at every $5 \mathrm{~min}$ and immediately mixed with $1 \mathrm{~mL}$ DPD solution $(8.0 \mathrm{mM})$. Free iodine concentration was determined colorimetrically according to the absorbance at $510 \mathrm{~nm}$ measured by a Varian Cary 50 spectrophotometer (APHA/AWWA/WEF, 2005). Controls in the absence of phenol were also measured. All experiments were carried out in triplicates, and the data were averaged. The standard deviation of this approach was within $5 \%$.

$$
\mathrm{IO}_{3}^{-}+8 \mathrm{I}^{-}+6 \mathrm{H}^{+} \rightarrow 3 \mathrm{I}_{2}^{-}+3 \mathrm{H}_{2} \mathrm{O}
$$

$\mathrm{IO}_{3}^{-}$and $\mathrm{I}^{-}$can comproportionate to form free iodine immediately (R7). By measure the increased formation of free iodine after mixing with excessive $\mathrm{I}^{-}$, the formation of $\mathrm{IO}_{3}{ }^{-}$can be inferred. In this study, 2 aliquots were withdrawn from the reaction solution at preset reaction time. One of them was spiked with $0.5 \mathrm{mM} \mathrm{I}^{-}$before the measurement of free iodine concentration; and the other was measured directly. Concentration of $\mathrm{IO}_{3}^{-}$was determined according to the difference of free iodine concentration. 


\subsection{Analysis of iodophenols}

Formation of iodophenols was explored in $100 \mathrm{~mL}$ flasks as batch reactors. The reactions were conducted at 40,50 , and $60^{\circ} \mathrm{C}$. Iodophenols generated in the reactions were enriched by solid phase extraction (SPE) using Waters Oasis hydrophilic-lipophilic balance (HLB) cartridges. Prior to extraction, the cartridges were activated by $5 \mathrm{~mL}$ methanol and $5 \mathrm{~mL}$ acidified Milli-Q water ( $\mathrm{pH}$ adjusted to 3.0 with $\mathrm{H}_{2} \mathrm{SO}_{4}$ ) sequentially. The quenched reaction solutions were percolated to the cartridges at a flow rate of $5 \mathrm{~mL} / \mathrm{min}$. After sample passage, the cartridges were rinsed with 2 $\mathrm{mL}$ Milli-Q water and $2 \mathrm{~mL} \mathrm{5 \%}$ aqueous methanol sequentially. The extracts were then eluted with $2 \mathrm{~mL}$ methanol. Monoiodophenols and triiodophenol were quantified by a Hitachi L-2000 high performance liquid chromatography (HPLC) equipped with an L-2455 diode array detector. The separation was performed on a C18 reverse-phase column (Hitachi LaChrom, $5 \mu \mathrm{M} \times 250$ $\mathrm{mm} \times 4.6 \mathrm{~mm}$ ) using a isocratic eluent comprised of $55 \%$ acetonitrile (with $0.1 \%$ acetic acid, v/v) and $45 \%$ water (with $0.1 \%$ acetic acid, v/v). The flow rate was $1 \mathrm{~mL} / \mathrm{min}$ and the detection wavelength was at $227 \mathrm{~nm}$. Quantification was performed by using multipoint calibration curves.

\subsection{HPLC-MS/MS analysis}

The enriched samples as described above were also analyzed using an Agilent 6410B triple quadrupole mass spectrometer equipped with an electron-spray ionization (ESI) source (Agilent Technologies, USA). The ESI was operated at negative ionization mode and mass analyzer at full scan mode (m/z 50-600). Other settings were as follows: capillary voltage $-4.0 \mathrm{kV}$, fragmentor $125 \mathrm{~V}$, nitrogen as $(>99.995 \%)$ desolvation gas at flow rate $10 \mathrm{~mL} / \mathrm{min}$, temperature $320^{\circ} \mathrm{C}$, nebulizer (nitrogen, >99.995\%) pressure 30 psi. 


\section{Results and discussion}

\subsection{Formation of free iodine}

$\mathrm{Br}^{-}$can be oxidized by $\mathrm{SO}_{4}{ }^{-}$to from bromine atom radicals $(\mathrm{Br} \bullet)$ which reacts with another $\mathrm{Br}$ to generate bromine radical $\left(\mathrm{Br}_{2}{ }^{-}\right)$. The radical bromine species couple to each other to give rise to free bromine $\left(\mathrm{Br}_{2} / \mathrm{HBrO}\right)$. These free and radical bromine species can be further oxidized to $\mathrm{BrO}_{3}{ }^{-}$when sufficient $\mathrm{SO}_{4}{ }^{-}$is present (Fang and Shang, 2012). Because $\mathrm{I}^{-}\left(\mathrm{E}_{\mathrm{I} / \mathrm{l} \bullet}^{0}=1.33 \mathrm{~V}\right.$ ) is

more readily oxidized than $\operatorname{Br}^{-}\left(\mathrm{E}_{\mathrm{Br} / \mathrm{Br} \bullet}^{0}=1.62 \mathrm{~V}\right)$, we hypothesize that similar transformation scheme also applies for $\mathrm{I}^{-}$. Thus, formation of both free iodine and $\mathrm{IO}_{3}^{-}$in heat/PS oxidation process was monitored and the data are shown in Fig. 1. As it can be seen, free iodine concentration increased gradually and reached a temporal maximum $(20.6 \mu \mathrm{M})$ in approximately $1.0 \mathrm{~h}$. Then the free iodine concentration decreased as the reaction proceeded, which could be explained by its further oxidation to $\mathrm{IO}_{3}{ }^{-}$by $\mathrm{SO}_{4}{ }^{-}$. Transformation of $\mathrm{Br}^{-}$was also examined at the same conditions for comparison. It appeared that $\mathrm{Br}^{-}$was oxidized to free bromine by $\mathrm{SO}_{4}{ }^{-}$ more rapidly (Fig. S1, Supplementary data). With an initial PS of $5.0 \mathrm{mM}$, it took approximately $1 \mathrm{~h}$ for free iodine to reach its temporal maximum while the maximum was observed in $14 \mathrm{~min}$ for free bromine.

$\mathrm{IO}_{3}{ }^{-}$was only detected after $0.5 \mathrm{~h}$ and then its concentration increased gradually and reached approximately $40 \mu \mathrm{M}$ in $8 \mathrm{~h}$ (Supporting data, Fig. S2). It should be noted that $\mathrm{IO}_{3}{ }^{-}$and $\mathrm{I}^{-}$ comproportionate to form free iodine immediately. Detection of $\mathrm{IO}_{3}{ }^{-}$indicates the depletion of $\mathrm{I}^{-}$. Accordingly, the sum of $\mathrm{IO}_{3}{ }^{-}$and free iodine accounted for more than $90 \%$ of the total iodine and the value did not varied significantly after $30 \mathrm{~min}$.

Formation of free iodine was markedly reduced in the presence of phenol, especially during the first $3.5 \mathrm{~h}$ (Fig. 1). This finding can be rationalized by the following reasons. First, the availability of $\mathrm{SO}_{4}{ }^{--}$for the reaction with $\mathrm{I}^{-}$was reduced due to the scavenging by phenol. 
Reaction between phenol and $\mathrm{SO}_{4}{ }^{--}$is nearly diffusion-controlled with a second-order rate constant of $8.8 \times 10^{9} \mathrm{M}^{-1} \mathrm{~s}^{-1}$ (Neta et al., 1977). The reaction rate constant between $\mathrm{I}^{-}$and $\mathrm{SO}_{4}{ }^{-}$is unknown, but according to the data in Fig. S1, it should be lower than that of the reaction between $\mathrm{Br}^{-}$and $\mathrm{SO}_{4}{ }^{--}\left(3.5 \times 10^{9} \mathrm{M}^{-1} \mathrm{~s}^{-1}\right)$ (Neta et al., 1977). Based on the kinetic constants, $\mathrm{SO}_{4}{ }^{--}$ was more likely to react with phenol than $\mathrm{I}^{-}$at the initial stage of the reaction when the concentrations of phenol and $\mathrm{I}^{-}$were both $0.05 \mathrm{mM}$. Thus, the formation of free iodine was inhibited. However, phenol scavenging of $\mathrm{SO}_{4}{ }^{--}$could not be the only reason responsible for the suppressed free iodine formation. A recent study by Feng et al. (2017) demonstrated that $\mathrm{I}^{-}$could facilitate the degradation of phenolic compounds in activated PS oxidation systems. It was also observed in this study that the presence of $\mathrm{I}^{-}$accelerated phenol degradation significantly as shown in Fig. 2. Such a result was obviously attributed to the reactions with RIS generated upon $\mathrm{I}^{-}$oxidation by $\mathrm{SO}_{4}{ }^{--}$. Oxidation of $\mathrm{I}^{-}$by $\mathrm{SO}_{4}{ }^{--}$forms radical iodine species $\left(\mathrm{I}^{\circ}, \mathrm{I}_{2}{ }^{-{ }^{-}}\right)$which couple to each other to form free iodine. Free iodine is a typical electrophile that can react with electron-rich compounds rapidly. Iodination occurs 15 times faster than chlorination in water halogenation process (Hatch, 1999). Therefore, free iodine could be depleted by reacting with phenol immediately after its formation. Note that, although the reaction rate of phenol oxidation by $\mathrm{SO}_{4}{ }^{-}$might be orders of magnitude higher than that of its iodination, the steady-state concentration of $\mathrm{SO}_{4}{ }^{-}$is usually in the range of $10^{-12}-10^{-15} \mathrm{M}$ in SR-AOPs (Yang et al., 2014), while the concentration of free iodine was at $10^{-6} \mathrm{M}$ level. The relatively high concentration of free iodine would compensate its lower reaction rate constant with phenol, making it possible that iodination of phenol outweighed its degradation by $\mathrm{SO}_{4}{ }^{--}$. In addition to free iodine, phenol could also react with the radical iodine species directly. According to Feng et al. (2017) the radical iodine species played an even more dominant role than $\mathrm{SO}_{4}{ }^{-}$in the degradation of phenolic compounds in activated PS oxidation systems in the presence of I'. Such reactions reduced the formation of free iodine. 


\subsection{Formation of iodophenols}

Scavenging of RIS, especially free iodine, by phenol was expected to result in the formation of iodinated intermediates, which were identified by HPLC. Free halogen reacts with phenols via electrophilic substitution orienting to the ortho and para positions of the hydroxyl group (Lu et al., 2004). As shown in Fig. S2 (Supplementary data), 2-iodophenol, 4-iodophenol and 2,4,6-triiodophenol were detected in accordance with this mechanism. Time-dependent formation of mono- and tri-iodophenol were shown in Fig. 3. It can be seen that formation of both 2-iodophenol and 4-iodophenol showed exactly the same trend as the reaction proceeded. However, the yield of the former was always approximately twice that of latter. This is also consistent with electrophilic substitution mechanism. Assuming the ortho and para positions have equal chance of being attacked by free halogen, but the former has two and the latter has only one. As a result, the yield of ortho substituted product would be twice that of para substituted one. 2,4,6-triiodophenol was also detected but its yield was at least an order of magnitude lower than that of monoiodophenol at identical conditions. MS analysis provided evidence of the formation of 2,4-diiodophenol. As shown in Fig. S4 (Supplementary data), a peak of $m / z 345$ was found after treatment, which was consistent with the molecular weight of diiodophenol (MW 346). Unfortunately, its formation could not be quantified due to the lack of authentic standard.

Formation of iodophenols in heat/PS system showed a first increase and then decrease tendency. The maximum concentrations of mono-iodophenols appeared at approximately $30 \mathrm{~min}$ (9.7 and 3.2 $\mu \mathrm{M}$ for 2-monoiodophenol and 4-monoiodophenol, respectively), in the solution initially containing $5.0 \mathrm{mM}$ PS, $0.05 \mathrm{mM} \mathrm{I}, 0.05 \mathrm{mM}$ phenol and at $50{ }^{\circ} \mathrm{C}$. Tri-iodophenol peaked at approximately $2.0 \mathrm{~h}$ with a much less yield $(1.5 \mu \mathrm{M})$. Overall, the identified mono-iodophenols accounted for a significant fraction of the transformed phenol during the initial stage of the reaction. For instance, more than $50 \%$ of the removed phenol was transformed to 
mono-halophenols in $0.5 \mathrm{~h}$ (Fig. 2 and 3). These data corroborate the conclusion that the RIS played an important role in the degradation of phenol in the system. Temperature played a critical role in governing the formation and transformation of iodophenols. When the temperature was elevated to $60^{\circ} \mathrm{C}$, the formation of monoiodophenols was greatly accelerated and reached their maximums in $10 \mathrm{~min}$. They completely disappeared in $1.0 \mathrm{~h}$. This result is reasonable because high temperature facilitates the activation of PS and, thus, generation of $\mathrm{SO}_{4}{ }^{-{ }^{-}}$and RIS. In contrast, when the temperature was decreased to $40^{\circ} \mathrm{C}$, mono- and tri-iodophenol were formed slowly and plateaued after $2.0 \mathrm{~h}$.

Removal of phenol were examined at initial phenol and free iodine concentrations of both 50 $\mu \mathrm{M}$ to evaluate the reactivity of free iodine toward phenol and its iodinated products. It was revealed that phenol removal was significantly faster than in heat/PS system with $70 \%$ elimination achieved within $1 \mathrm{~min}$ and $90 \%$ in $10 \mathrm{~min}$ (data not shown). The nearly 1:1 stoichiometric ratio of the reaction between free iodine and phenol indicates that mono-iodophenols were the main products and they were less reactive than the parent phenol toward free iodine. Thus, the further transformation of mono-iodophenols (Fig. 3) in heat/PS system was more likely ascribe to the reaction with $\mathrm{SO}_{4}{ }^{--}$and/or the radical iodine species than free iodine, in spite latter contributed the degradation of parent phenol and formation of mono-iodophenols significantly. This also explains the low yield of tri-iodophenol, because reaction with radical halogen species is usually a one-electron oxidation process which is unlikely to lead to organic halogens (Parker and Mitch, 2016).

\subsection{Formation of I-DBPs}

It is well recognized that halogenation of phenolic compounds results in the formation of halogenated DBPs including trihalomethanes (THMs) and haloacetic acids (HAAs) in water chlorination (Bichsel and Gunten, 2000, Lu et al., 2004). During their formation, electrophilic attack of phenolic precursors by free halogen is the key step (Bichsel and Gunten, 2000). Thus, 
formation of iodine substituted phenols and their subsequent disappearance were presumed to lead to the formation of I-DBPs. In this work, substantial formation of iodoform and DIAA was verified (Fig. 4). TIAA was also formed but its yield was significantly less than that of DIAA. Formation of MIAA was even less. Similar formation and speciation of I-DBPs were also found when $\mathrm{I}^{-}$concentration decreased to $5 \mu \mathrm{M}$ (Fig. S5, Supplementary data). Preferential formation of DIAA over iodoform and TIAA in heat/PS system is indeed distinct from that in conventional halogenation processes where formation of iodoform was more favored while IAAs formation were under detection limits (Fig. S6, Supplementary data). However, such a distribution seems characteristic to the DBPs formation in SR-AOPs. Wang et al. found that more DBAA was produced than TBAA in $\mathrm{CuFe}_{2} \mathrm{O}_{4} / \mathrm{PMS}$ oxidation process in the presence of $\mathrm{Br}^{-}$(Wang et al., 2014). Our earlier studies demonstrated similar speciation of bromoacetic acids in heat/PS and $\mathrm{Co}^{2+} / \mathrm{PMS}$ oxidation processes (Lu et al., 2015, Liu et al., 2015).

Similar to the iodine substituted phenolic intermediates, time-dependent formation of the 4 I-DBPs generally showed similar trends toward the change of temperature. There was a lag period before the formation of iodoform, MIAA, and TIAA. As illustrated in Fig. 4, these I-DBP species were not observed until $2.0 \mathrm{~h}$ later at $50^{\circ} \mathrm{C}$. After that, the concentrations of iodoform and TIAA increased abruptly and reached 0.04 and $0.03 \mu \mathrm{M}$, respectively, in approximately $4.0 \mathrm{~h}$ before decreasing. It is evident that the formation of the above I-DBPs followed the disappearance of the iodophenol intermediates, suggesting that they were the products of the iodophenols subjected to further iodination or oxidation reactions. Note that, DIAA was formed substantially faster than the other 3 I-DBPs. Its concentration increased rapidly and reached 1.24 $\mu \mathrm{M}$ in 45 min before decreasing gradually. Such a concentration corresponds to a molar yield of $2.5 \%$ (in relative to phenol) which is even close to the maximum yield of tri-iodophenol (2.9\%). In addition, its generation was almost concomitant with that of monoiodophenols and iodination of monoiodophenol generated preferentially iodoform and ICAA (Fig. S7, Supplementary data). 
All of the facts suggest that DIAA was produced via alternative reaction pathway(s) rather than from iodophenols transformation. When the working temperature was increased to $60^{\circ} \mathrm{C}$, the reactions proceeded considerably more rapidly than at $50^{\circ} \mathrm{C}$. As shown in Fig. 4 , the formation of iodoform and TIAA was accelerated and their maximum yields reached 0.05 and $0.04 \mu \mathrm{M}$, respectively, in $1.0 \mathrm{~h}$ before decreasing, while the peak concentrations were found in $4.0 \mathrm{~h}$ at $50^{\circ} \mathrm{C}$. However, the formation rate of DIAA appeared less sensitive to the change of working temperature. The time for it reaching the maximum concentration decreased from 0.8 to $0.3 \mathrm{~h}$ as the temperature increased from 40 to $60^{\circ} \mathrm{C}$. Working temperature also showed little influence on the maximum yield of DIAA, while those of the other I-DBPs increased pronouncedly as the increase of temperature. All these facts reinforce the argument that different mechanisms involved in the formation of DIAA and the other I-DBPs.

Similar trends of bromoform and bromoacetic acids formation have been reported by our previous research on $\mathrm{Co}^{2+} / \mathrm{PMS}$ oxidation of phenol in the presence of $\mathrm{Br}^{-}$(Liu et al., 2015). However, higher yields of Br-DBPs were observed. The maximum yields of bromoform, monobromoacetic acid, dibromoacetic acid, and tribomoacetic acid were approximately 70.0, 4.4, 75.0, and 75.0 mmole per mole $\mathrm{Br}^{-}$, respectively (Liu et al., 2015). The yields of the I-analogs were found to be at least an order of magnitude lower than that of Br-DBPs. The values for iodoform, MIAA, DIAA and TIAA were measured to be $0.90,0.11,24.80$, and 0.8 mmole per mole $\mathrm{I}^{-}$, respectively. The reduced formation of I-DBPs could be partially attributed to the relatively low reaction rate of $\mathrm{I}^{-}$oxidation by $\mathrm{SO}_{4}{ }^{-}$than that of $\mathrm{Br}^{-}$. As such, $\mathrm{SO}_{4}{ }^{-}$has more chance to react with phenol compared with the system where $\mathrm{I}^{-}$is replaced by equal amount of $\mathrm{Br}^{-}$. In other words, less phenol is available for halogenation in system with $\mathrm{I}^{-}$, leading to less I-DBPs.

PS dose is another critical factor governing the formation of I-DBPs. As it can be seen in Fig. 5, the maximum yields of I-DBPs decreased but their appearance time moved forward as PS concentration increased. For instance, at PS concentration of $0.5 \mathrm{mM}$, the yield of DIAA reached 
its maximum $(1.06 \mu \mathrm{M})$ in $2 \mathrm{~h}$ and then decreased. Iodoform, MIAA, and TIAA were, however, not observed until $8.0 \mathrm{~h}$ later. The maximum yields of iodoform and TIAA appeared in $12.0 \mathrm{~h}$ and the values were 0.14 and $0.59 \mu \mathrm{M}$, respectively. MIAA concentration kept increasing within the investigated time period. When PS dose was increased to $5.0 \mathrm{mM}$, DIAA was formed more rapidly and the maximum concentration of $1.01 \mu \mathrm{M}$ appeared at 15 min. Iodoform, MIAA, and TIAA reached their temporary maximums of $0.04,0.005$, and $0.04 \mu \mathrm{M}$, respectively, in $3 \mathrm{~h}$. It is noteworthy that, at all PS doses, DIAA formation was always considerably faster and higher than iodoform and TIAA.

The decrease of I-DBPs implies their degradation by excessive $\mathrm{SO}_{4}{ }^{-}$, which was verified by additional experiments investigating the stability of individual I-DBP in heat/PS system (Fig. S8, Supplementary data). It was found that I-DBPs degradation followed first-order kinetics $\left(r^{2}>0.90\right)$. Half-life times of iodoform and TIAA were 1.0 and $1.5 \mathrm{~h}$, respectively, in the presence of $1.0 \mathrm{mM}$ PS at $50{ }^{\circ} \mathrm{C}$. The half-life times of MIAA and DIAA were over $3.0 \mathrm{~h}$. It is evident that DIAA is more resistant to $\mathrm{SO}_{4}{ }^{--}$oxidation than the other I-DBPs. This may explain, at least partially, the higher yield of DIAA than that of TIAA or iodoform. When I-DBPs were degraded by $\mathrm{SO}_{4}{ }^{-}$, organic iodine was probably converted back to inorganic $\mathrm{I}^{-}$, which was expected to be oxidized by $\mathrm{SO}_{4}{ }^{--}$to form RIS again, as evidenced by the results displayed in Fig. 1. Although the free iodine formation was suppressed during the first $3.0 \mathrm{~h}$ in the presence of phenol, its re-accumulation was found between 4.0 - $5.0 \mathrm{~h}$ (Fig. 1). This probably corresponds to the transformation of organic iodine to free iodine again. It is presumed that the free iodine formed in such a pathway can participate in the iodination of remaining organics and be transformed to organic iodine again. However, such reactions were insignificant and the free iodine was most likely oxidized by $\mathrm{SO}_{4}{ }^{-}$ directly to higher oxidation state in the present study because the free iodine transformation rate after $5 \mathrm{~h}$ was close to the system with phenol absent. 


\subsection{Reaction scheme}

According to the above data and discussion, the transformation pathway of $\mathrm{I}^{-}$in heat/PS system can be proposed as shown in Fig. 6. $\mathrm{I}^{-}$is oxidized by $\mathrm{SO}_{4}{ }^{-{ }^{-}}$to form RIS including both radical and free iodine, which attack phenol yielding iodophenols and DIAA. The iodophenols undergo further iodination and/or oxidation to generate iodoform, MIAA, and TIAA. These iodinated organics are unstable towards $\mathrm{SO}_{4}{ }^{--}$attack and could be degraded to form $\mathrm{I}^{-}$again. In principle, the released I' can be oxidized to form RIS which reacts with the organics in the solution again, if excessive $\mathrm{SO}_{4}{ }^{-}$is available. In this way, $\mathrm{I}^{-}$can be cycled for multiple times until either $\mathrm{SO}_{4}{ }^{--}$is depleted or it is converted to higher oxidation states such as $\mathrm{IO}_{3}{ }^{-}$. Comparing the data shown in Fig. 1 and Fig. 4, it can be seen that the decline of organic iodine was accompanied by the re-accumulation of free iodine. The free iodine formed $(3.5-4.5 \mathrm{~h})$ during this particular period of time was mostly attributed to the oxidation of recycled $\mathrm{I}^{-}$. We assume that a portion of $\mathrm{I}^{-}$ will end in forms of organic iodine, including I-DBPs, if $\mathrm{SO}_{4}{ }^{-}$is depleted before $\mathrm{I}^{-}$is completely converted. Such a scenario was likely seen in the treatment with $0.5 \mathrm{mM}$ PS (Fig. 5).

\subsection{Implications}

Heat/PS is a promising technology for soil and groundwater remediation as it can be easily controlled and requires no additional reagents. This technology is particular attractive when it is combined with in situ thermal remediation technologies (Waldemer et al, 2007). According to the findings of this study, formation of I-DBPs is likely when heat/PS technology is applied to environmental matrices containing I- Because I-DBPs are highly cytotoxic and genotoxic, their potential formation should be an important consideration in the evaluation of the feasibility of this technology. $\mathrm{I}^{-}$is commonly found in the environment. In natural waters, it has an average concentration of $20 \mu \mathrm{g} / \mathrm{L}$ (Moran et al., 2002). At certain geological conditions or due to seawater intrusion, $\mathrm{I}^{-}$concentration can exceed $50 \mu \mathrm{g} / \mathrm{L}$ in groundwater (Bichsel, 2000). Though the concentration of $\mathrm{I}^{-}$is usually significantly lower than that of $\mathrm{Br}^{-}$in environmental matrices and 
oxidation of $\mathrm{Br}^{-}$by $\mathrm{SO}_{4}{ }^{--}$appears more rapidly than $\mathrm{I}^{-}$, the activation of $\mathrm{I}^{-}$in heat/PS system is still expected because $\mathrm{I}^{-}$can be rapidly oxidized by reactive bromine species. As such, both Br-DBPs and I-DBPs would be generated. However, their formation and speciation under environmentally relevant conditions warrant further study.

\section{Conclusions}

This study demonstrated the formation of I-DBPs including iodoform, MIAA, DIAA, and TIAA in heat/PS system in the presence of $\mathrm{I}^{-}$. Formation of I-DBPs was attributed to the generation of RIS due to the oxidation of $\mathrm{I}^{-}$by $\mathrm{SO}_{4}{ }^{-}$. Iodophenols, including 2-iodophenol, 4-iodophenol, and 2,4,6-triiodophenol, were detected as precursors of iodoform, MIAA, and TIAA. DIAA was likely formed via disparate pathway rather than from iodophenols transformation. The reaction process was governed by the concentration of $\mathrm{SO}_{4}{ }^{-}$in the solution. Thus, increasing temperature or persulfate dose accelerated the reaction process. In the presence of excessive $\mathrm{SO}_{4}{ }^{-}$, I-DBPs can be further degraded, and $\mathrm{I}^{-}$is presumed to transformed to $\mathrm{IO}_{3}{ }^{-}$ ultimately. However, insufficient $\mathrm{SO}_{4}{ }^{-}$could lead partial $\mathrm{I}^{-}$ending up as organic forms such as I-DBPs. Such scenario can be expected in soil remediation where the supply of NOM could be infinity making $\mathrm{SO}_{4}{ }^{-}$relatively inadequate.

\section{Acknowledgments}

This research was supported by the National Science Foundation of China (51578294) and the Priority Academic Program Development (PAPD) of Jiangsu Higher Education Institute.

\section{Appendix A. Supplementary data}

Supplementary data associated with this article can be found in the online version.

\section{References}

Adewuyi, Y.G., Sakyi, N.Y., 2014. Removal of Nitric Oxide by Aqueous Sodium Persulfate Simultaneously Activated by Temperature and $\mathrm{Fe}^{2+}$ in a Lab-scale Bubble Reactor. Ind. Eng. 
Chem. Res. 53(2), 828-839.

Anipsitakis, G.P., Dionysiou, D.D., 2003. Degradation of organic contaminants in water with sulfate radicals generated by the conjunction of peroxymonosulfate with cobalt. Environ. Sci. Technol. 37 (20), 4790-4797.

Anipsitakis, G.P., Dionysiou, D.D., Gonzalez, M.A., 2006. Cobalt-mediated activation of peroxymonosulfate and sulfate radical attack on phenolic compounds. implications of chloride ions. Environ. Sci. Technol. 40(3), 1000-1007.

Bennedsen, L.R., Muff, J. Søgaard, E.G., 2012. Influence of chloride and carbonates on the reactivity of activated persulfate. Chemosphere 86(11), 1092-1097.

Bichsel, Y., 2000. Behavior of iodine species in oxidative processes during drinking water treatment, /. Zürich.

Bichsel, Y., Gunten, U.V., 2000. Formation of iodo-trihalomethanes during disinfection and oxidation of iodide-containing waters. Environ. Sci. Technol. 34(13), 2784-2791.

Buxton, G.V., Greenstock, C.L., Helman, W.P., Ross, A.B., 1988. Critical Review of rate constants for reactions of hydrated electrons, hydrogen atoms and hydroxyl radicals $\left(\cdot \mathrm{OH} / \cdot \mathrm{O}^{-}\right.$in Aqueous Solution. Journal of Physical \& Chemical Reference Data $17(2)$, 513-886.

Chen, B., 2011. Hydrolytic Stabilities of Halogenated Disinfection Byproducts: Review and Rate Constant Quantitative Structure-Property Relationship Analysis. Environ. Eng. Sci. 28(6), 385-394.

Chu, W., Hu, J., Bond, T., Gao, N., Xu, B., Yin, D., 2016. Water temperature significantly impacts the formation of iodinated haloacetamides during persulfate oxidation. Water Res. 98, 47-55.

Ding, G., Zhang, X., 2009. A picture of polar iodinated disinfection byproducts in drinking water 
by (UPLC/) ESI-tqMS. Environ. Sci. Technol. 43(24), 9287-9293.

Fang, C., Xiao, D., Liu, W., Lou, X., Zhou, J., Wang, Z., Liu, J., 2016. Enhanced AOX accumulation and aquatic toxicity during 2,4,6-trichlorophenol degradation in a Co(II)/peroxymonosulfate/ $\mathrm{Cl}^{-}$system. Chemosphere $144,2415-2420$.

Fang, J.Y., Shang, C., 2012. Bromate formation from bromide oxidation by the UV/persulfate process. Environ. Sci. Technol. 46(16), 8976-8983.

Feng, Y., Lee, P., Wu, D., Shih, K., 2017. Rapid selective ccircumneutral degradation of phenolic pollutants using peroxymonosulfate-iodate metal-free oxidation: Role of iodine atoms. Environ. Sci. Technol. 51(4), 2312-2320.

Guan, C., Jiang, J., Luo, C., Pang, S., Pang, S., Jiang, C., Ma, J., Jin, Y. and Li, J, 2017. Transformation of iodide by carbon nanotube activated peroxydisulfate and formation of iodoorganic compounds in the presence of natural organic matter. Environ. Sci. Technol. $51(1), 479-487$.

Guan, Y.H., Ma, J., Li, X.C., Fang, J.Y., Chen, L.W., 2011. Influence of pH on the formation of sulfate and hydroxyl radicals in the UV/peroxymonosulfate system. Environ. Sci. Technol. 45(21), 9308-9314.

Hasegawa, K., Neta, P., 1978. Rate constants and mechanisms of reaction of $\mathrm{Cl}_{2}{ }^{-}$radicals. J. Phys. Chem. 82(8).

Hatch, G.L., 1999. Comment on "Chlorination and Formation of Organoiodinated Compounds: The Important Role of Ammonia". Environ. Sci. Technol. 33(2), 366-366.

Huie, R.E., Clifton, C.L., Neta, P., 1991. Electron transfer reaction rates and equilibria of the carbonate and sulfate radical anions. Int. J. Radiat. Appl. Instrum. C. Radiat. Phys. Chem. $38(5), 477-481$. 
Hodgeson, J., Collins, J., Barth, R., Munch, D.,Munch, J., Pawlecki, A., 1995. Method-552.2 Determination of Haloacetic Acids and Dalapon in Drinking Water by Liquid-liquid Extraction, Derivatization and Gas Chromatography with Electron-Capture Detection. Methods for the Determination of Organic Compounds in Drinking Water, Supplement III. USEPA, Office of Water, Technical Support Center, 26 W. Martin Luther King Dr., Dincinnati, OH 45268.

Hu, P,. Long, M., 2016. Cobalt-catalyzed sulfate radical-based advanced oxidation: A review on heterogeneous catalysts and applications. Appl. Catal. B Environ. 181, 103-117.

Ji, Y., Kong, D., Lu, J., Hao, J., Kang, F., Yin, X., Zhou, Q., 2016. Cobalt catalyzed peroxymonosulfate oxidation of tetrabromobisphenol A: Kinetics, reaction pathways, and formation of brominated by-products. J. Hazard. Mater. 313, 229-237.

Khan, J. A., He, X., Shah, N. S., Khan, H. M., Hapeshi, E., Fatta-Kassinos, D., Dionysios D. D., 2014. Kinetic and Mechanism Investigation on the Photochemical Degradation of Atrazine with Activated $\mathrm{H}_{2} \mathrm{O}_{2}, \mathrm{~S}_{2} \mathrm{O}_{8}{ }^{2-}$ and $\mathrm{HSO}_{5}{ }^{-}$. Chem. Eng. J. 252(18), 393-403.

Khiari, D., Bruchet, A., Gittelman, T., Matia, L., Barrett, S., Suffet, I. H., Hund, R., 1999. Distribution-generated taste-and-odor phenomena. Water Sci.Technol. 40(6), 129-133.

Li, J., Jin, J., Zhou, y., Pang, S.-Y., Gao, Y., Jiang, C., Ma, J., Jin, Y., Yang, Y., Liu, G., Wang, L. and Gian, C, 2017. Kinetics of Oxidation of Iodide $\left(\mathrm{I}^{-}\right)$and Hypoiodous Acid (HOI) by Peroxymonosulfate (PMS) and Formation of Iodinated Products in the PMS:I- ${ }^{-}$NOM System. Environ. Sci. Technol. 4(2), 76-82.

Liu, C., Salhi, E., Croué, J. P., von Gunten, U., 2014. Chlorination of iodide-containing waters in the presence of CuO: Formation of periodate. Environ. Sci. Technol. 48(22), 13173-13180.

Liu, K., Lu, J., Ji, Y., 2015. Formation of brominated disinfection by-products and bromate in cobalt catalyzed peroxymonosulfate oxidation of phenol. Water Res. 84, 1-7. 
Lu, J., Benjamin, M.M., Korshin, G.V., Gallard, H., 2004. Reactions of the flavonoid hesperetin with chlorine: a spectroscopic study of the reaction pathways. Environ. Sci. Technol. 38(17), 4603-4611.

Lu, J., Wu, J., Ji, Y., Kong, D., 2015. Transformation of bromide in thermo activated persulfate oxidation processes. Water Res. 78, 1-8.

Lu, J., Wei, D., Ji, Y., Kong, D., Huang, Q., 2016. Natural organic matter exposed to sulfate radicals increases its potential to form halogenated disinfection byproducts. Environ. Sci Technol. 2016, 50 (10), 5060-5067

Lutze, H. V., Bakkour, R., Kerlin, N., Sonntag, C. V., Schmidt, T. C., 2014. Formation of bromate in sulfate radical based oxidation: mechanistic aspects and suppression bydissolved organic matter. Water Res, 53(8), 370-377.

Munch, D., Hautman, D., 1995. Method-5521.1: Determination of Chlorination Disinfection Byproducts, Chlortinated Solvents, and Halogenated Pesticides/Herbicides in Drinking water by Liquid-liquid Extraction and Gas Chromatography with Electron-capture Detection. Methods for the Determination of Organic Compounds in Drinking Water. USEPA, Office of Water, Technical Support Center, 26 W. Martin Luther King Dr., Dincinnati, OH 45268.

Magazinovic, R.S., Nicholson, B.C., Mulcahy, D.E., Davey, D.E., 2004. Bromide levels in natural waters: its relationship to levels of both chloride and total dissolved solids and the implications for water treatment. Chemosphere 57(4), 329-335.

Moran, J.E., Oktay, S.D., Santschi, P.H., 2002. Sources of iodine and iodine 129 in rivers. Water Resour. Res. 38(38). 24-1-24-10.

Neta, P., Madhavan, V., Zemel, H., Fessenden, R. W., 1977. Rate constants and mechanism of reaction of so/sub 4/. - with aromatic compounds. [pulse radiolysis study]. J. Am. Chem. Soc.; (United States), 99:1. 
Oh, W.D., Dong, Z., Lim, T.T., 2016. Generation of sulfate radical through heterogeneous catalysis for organic contaminants removal: Current development, challenges and prospects. Appl. Catal. B Environ. 194, 169-201.

Park, K. M. and Mitch, W. A., 2016. Halogen radicals contribute to photooxidation in coastal and estuarine waters. Natl. Acad. Sci. USA., 113(21), 5868-5873.

Pera-Titus, M., Garcia-Molina, V., Baños, M.A., Giménez, J., Esplugas, S., 2004. Degradation of chlorophenols by means of advanced oxidation processes: a general review. Appl. Catal. B Environ 47(4), 219-256.

Plewa, M.J., Kargalioglu, Y., Vankerk, D., Minear, R.A., Wagner, E.D., 2002. Mammalian cell cytotoxicity and genotoxicity analysis of drinking water disinfection by-products. Environ Mol. Mutagen. 40(2), 134-142.

Plewa, M. J., Wagner, E. D., Richardson, S. D., Jr, T. A., Woo, Y. T., Mckague, A. B., 2004. Chemical and biological characterization of newly discovered iodoacid drinking water disinfection byproducts. Environ. Sci. Technol. 38(18), 4713-22.

Plewa, M.J., Wagner, E.D., 2009. Quantitative Comparative Mammalian cell cytotoxicity and genotoxicity of Selected Classes of Drinking water disinfection by-products, AmericanWater Research Foundation.

Richardson, S.D., Fasano, F., Ellington, J.J., Crumley, F.G., Buettner, K.M., Evans, J.J., Blount, B.C., Silva, L.K., Waite, T.J., Luther, G.W., 2008 Occurrence and mammalian cell toxicity of iodinated disinfection byproducts in drinking water. Environ. Sci. Technol. 42(22), $8330-8338$.

Shen, J. M., Chen, Z. L., Xu, Z. Z., Li, X. Y., Xu, B. B., Qi, F., 2008. Kinetics and mechanism of degradation of p-chloronitrobenzene in water by ozonation. J. Hazard. Mater. 152(3), 
1325-1331.

Tsitonaki, A., Petri, B., Crimi, M., Mosbæk, H., Siegrist, R.L., Bjerg, P.L., 2010. In Situ Chemical Oxidation of Contaminated Soil and Groundwater Using Persulfate: A Review. Critical Reviews in Environ. Sci. Technol. 40(1), 55-91.

Wang, Y., Le, R.J., Zhang, T., Croué, J.P., 2014. Formation of brominated disinfection byproducts from natural organic matter isolates and model compounds in a sulfate radical-based oxidation process. Environ. Sci. Technol. 48(24), 14534-14542.

Waldmer, R.H., Tratnyek, P.G., Johnson, R.L., Nurmi, J.T., 2007. Oxidation of chlorinated ethenes by heat activated persulfate: Kinetics and products. Environ. Sci. Technol. 41(3), $1010-1015$.

Xie, Y., 2003. Disinfection Byproducts in Drinking Water: Formation, Analysis, and Control. Crc Press.

Xie, W., Wei, D., Kong, D., Ji, Y., Lu, J., Yin, X., 2016. Formation of halogenated disinfection by-products in cobalt-catalyzed peroxymonosulfate oxidation processes in the presence of halides. Chemosphere, 154, 613-619.

Yang, Y., Pignatello, J.J., Ma, J., Mitch, W.A., 2014. Comparison of halide impacts on the efficiency of contaminant degradation by sulfate and hydroxyl radical-based advanced oxidation processes (AOPs). Environ. Sci. Technol. 48(4), 2344-2351.

Yang, Y., Pignatello, J.J., Ma, J., Mitch, W.A., 2016. Effect of matrix components on $\mathrm{UV} / \mathrm{H}_{2} \mathrm{O}_{2}$ and $\mathrm{UV} / \mathrm{S}_{2} \mathrm{O}_{8}{ }^{2-}$ advanced oxidation processes for trace organic degradation in reverse osmosis brines from municipal wastewater reuse facilities. Water Res. 89, 192-200.

Ye, T., Xu, B., Lin, Y. L., Hu, C. Y., Xia, S. J., Lin, L., Mwakagenda, S.A., Gao, N. Y., 2012. Formation of iodinated disinfection by-products during oxidation of iodide-containing water with potassium permanganate. J. Hazard. Mater. 241-242(9), 3006-14. 
Ye, T., Xu, B., Lin, Y. L., Hu, C. Y., Lin, L., Zhang, T. Y., Gao, N. Y., 2013. Formation of iodinated disinfection by-products during oxidation of iodide-containing waters with chlorine dioxide. Water Res. 47(9), 3006-3014.

Yeo, J., Choi, W., 2009. Iodide-Mediated Photooxidation of Arsenite under 254 nm Irradiation. Environ. Sci. Technol. 43(10), 3784-3788.

Zeng, T., Zhang, X., Wang, S., Niu, H., Cai, Y., 2015. Spatial Confinement of a $\mathrm{Co}_{3} \mathrm{O}_{4}$ Catalyst in Hollow Metal-Organic Frameworks as a Nanoreactor for Improved Degradation of Organic Pollutants. Environ. Sci. Technol. 49(4), 2350-2357.

Zhang, B. T., Zhang, Y., Teng, Y., Fan, M., 2014. Sulfate radical and its application in decontamination technologies. Crit. Rev. in Environ. Sci. Technol. 45(16), 536-545 


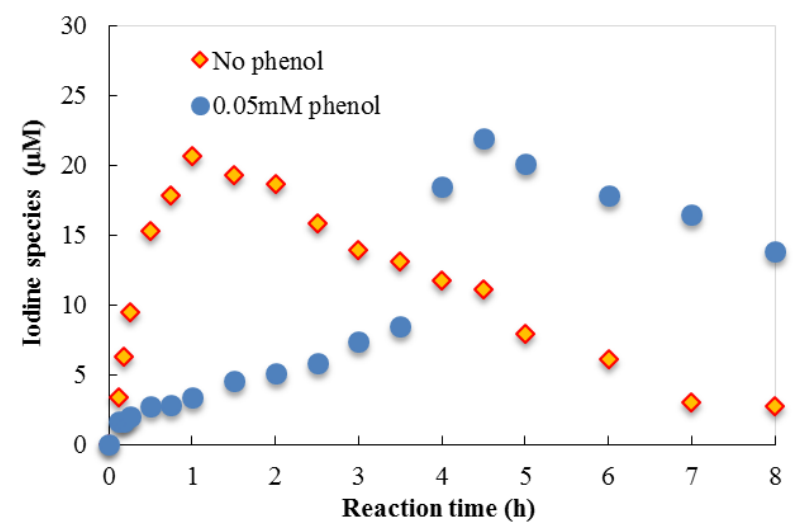

Fig. 1. Formation of free iodine in heat/PS system in the presence and absence of phenol.

$$
[\mathrm{PS}]_{0}=5 \mathrm{mM}, \mathrm{T}=50{ }^{\circ} \mathrm{C}, \mathrm{pH}=7.0,[\mathrm{phenol}]_{0}=0.05 \mathrm{mM} \text {. }
$$




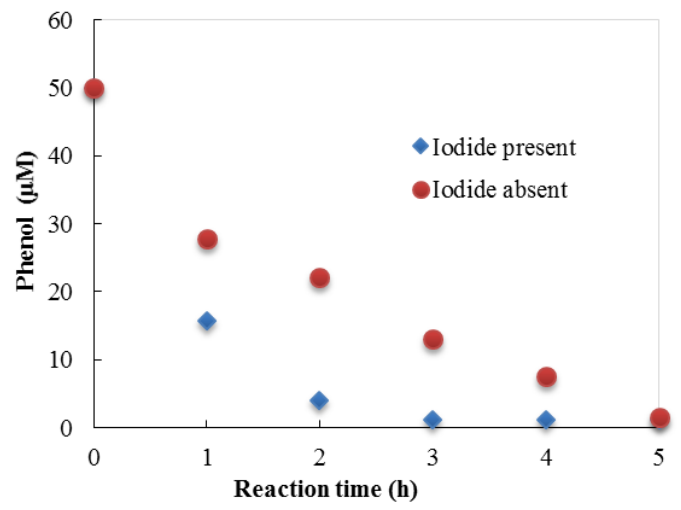

Fig. 2. Removal of phenol in heat/PS system in the presence and absence of $\mathrm{I}^{-}$. $[\mathrm{PS}]_{0}=5 \mathrm{mM}$,

$$
\mathrm{T}=50{ }^{\circ} \mathrm{C}, \mathrm{pH}=7.0,\left[\mathrm{I}^{-}\right]_{0}=0.05 \mathrm{mM} \text {. }
$$



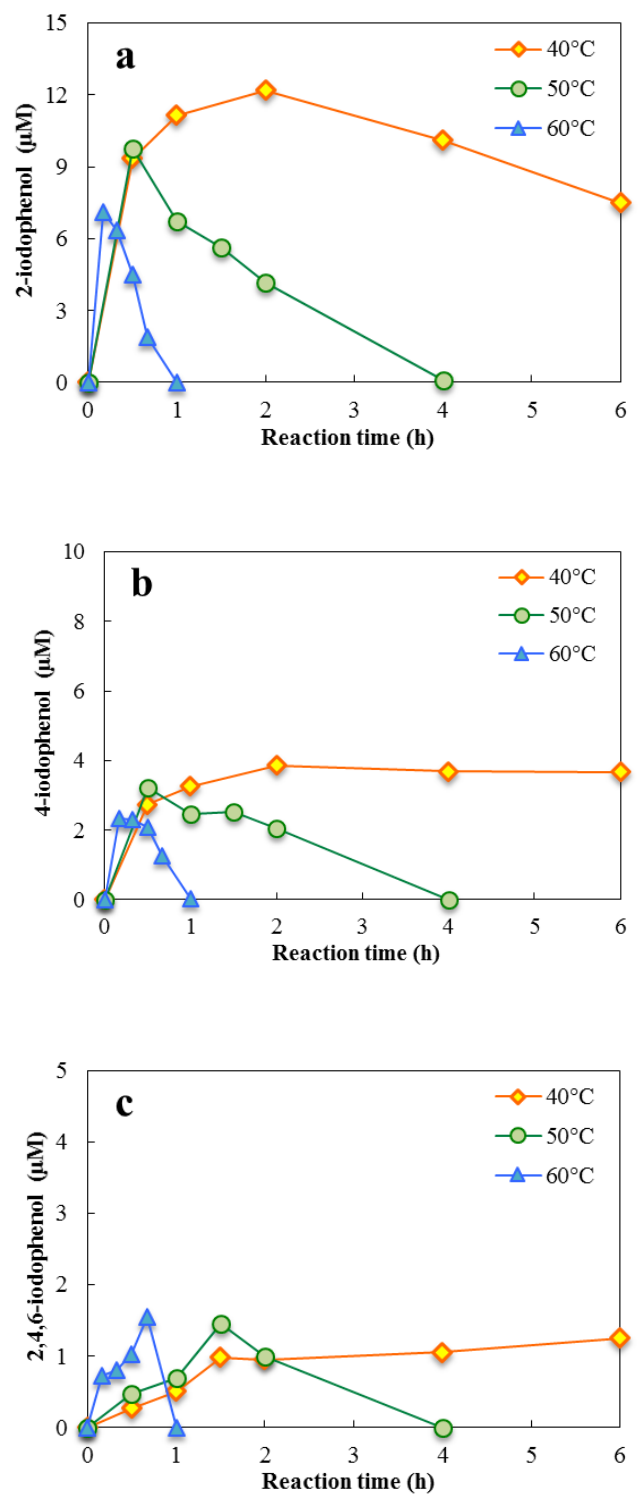

Fig. 3. Formation of iodophenols in heat/PS system in the presence of phenol and I'.

$[\text { phenol }]_{0}=0.05 \mathrm{mM} .\left[\mathrm{I}^{-}\right]_{0}=0.05 \mathrm{mM},[\mathrm{PS}]_{0}=5 \mathrm{mM}, \mathrm{T}=40,50,60{ }^{\circ} \mathrm{C}, \mathrm{pH}=7.0$, (a) 2-iodophenol, (b) 4-iodophenol, (c)2, 4, 6-triiodophenol. 

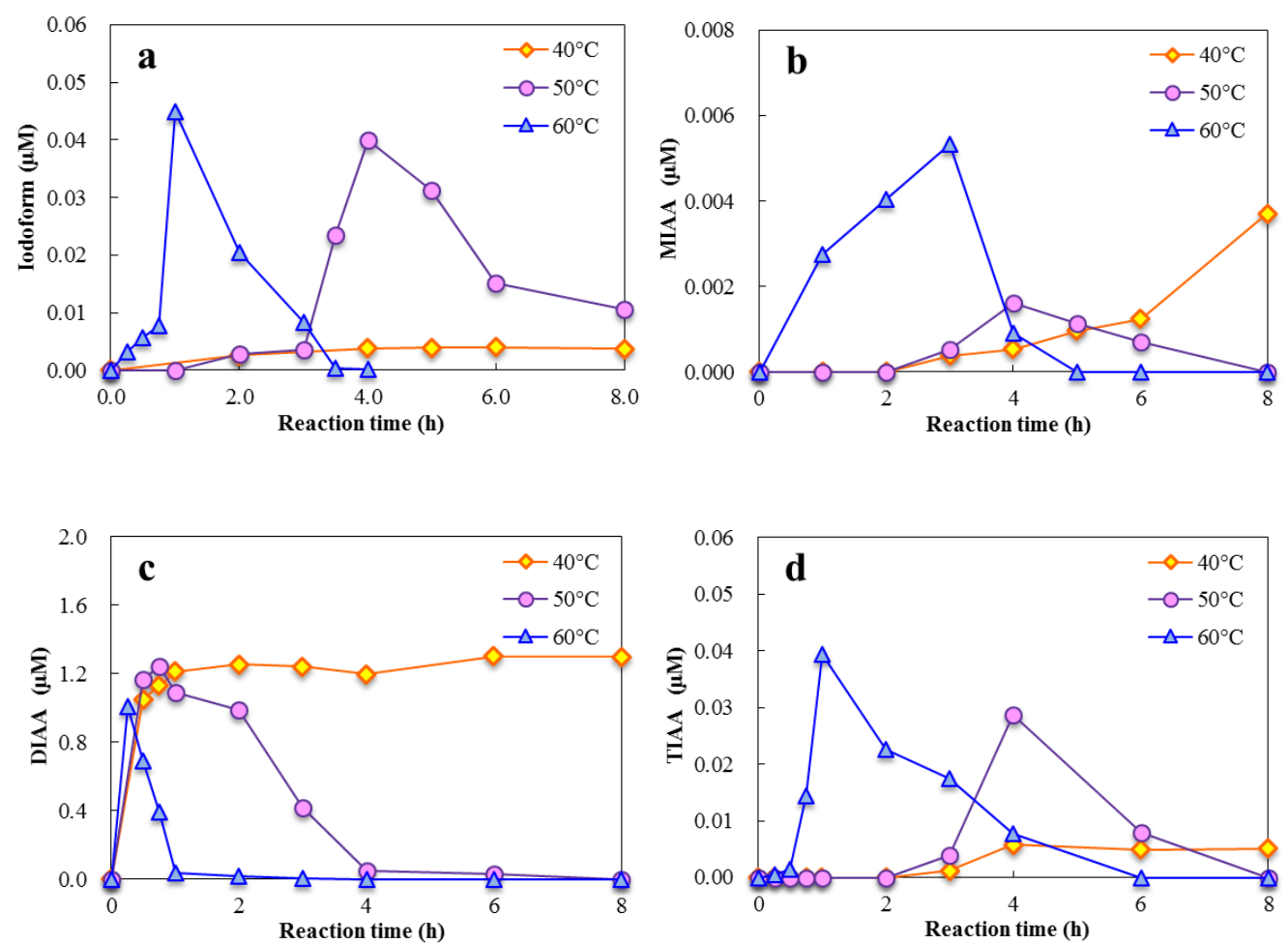

Fig. 4. Time-dependent formation of I-DBPs in heat/PS system in the presence of phenol and $\mathrm{I}^{-}$. [phenol $]_{0}=0.05 \mathrm{mM} .\left[\mathrm{I}^{-}\right]_{0}=0.05 \mathrm{mM},[\mathrm{PS}]_{0}=5 \mathrm{mM}, \mathrm{T}=40,50,60^{\circ} \mathrm{C}, \mathrm{pH}=7.0$, (a) Iodoform, (b) MIAA, (c) DIAA , (d) TIAA. 

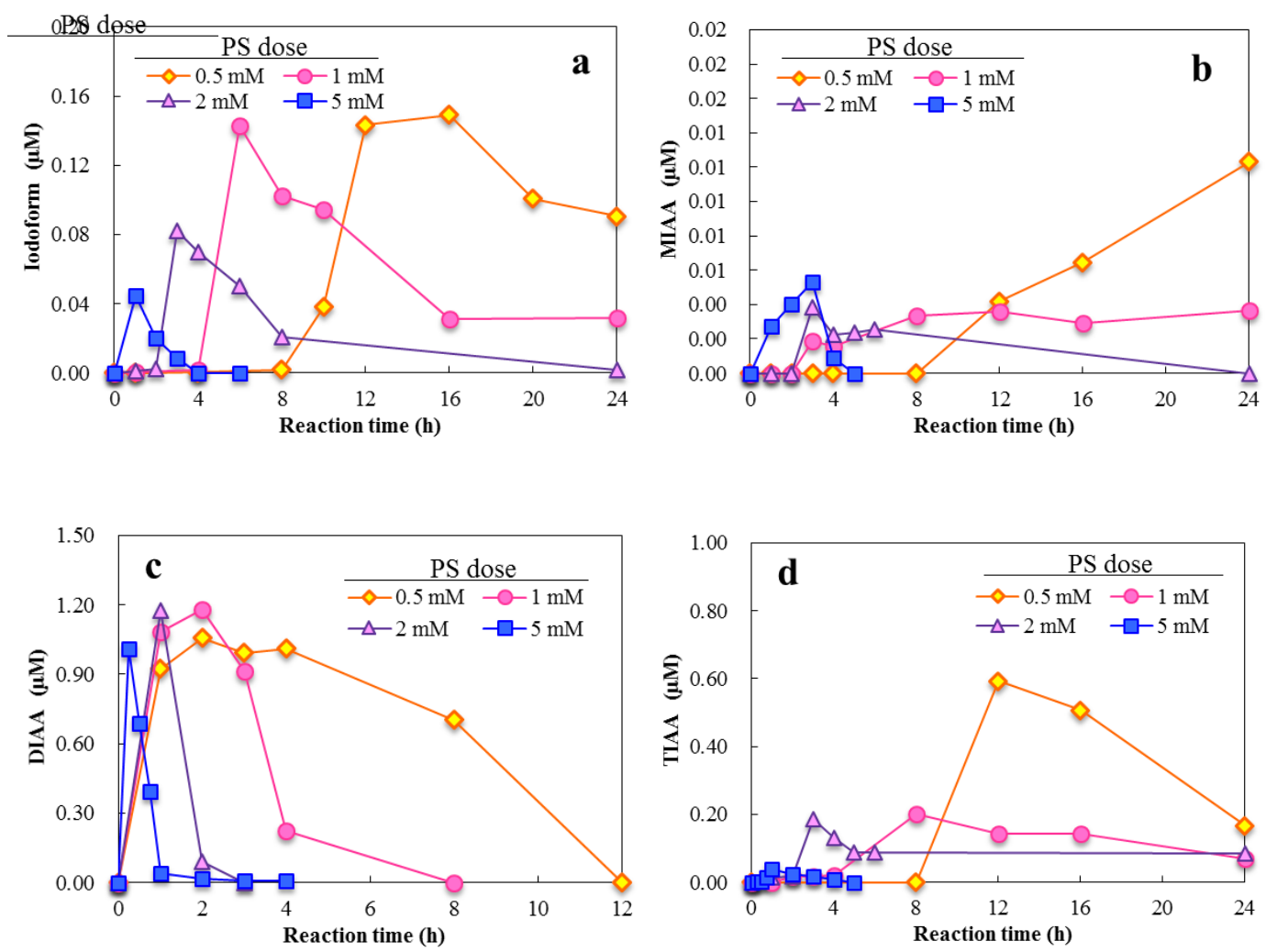

Fig. 5. Effects of initial PS concentration on the formation of I-DBPs in heat/PS system in the presence of phenol and $\mathrm{I}^{-}$. [phenol $]_{0}=0.05 \mathrm{mM}$. $\left[\mathrm{I}^{-}\right]_{0}=0.05 \mathrm{mM}, \mathrm{T}=60^{\circ} \mathrm{C}, \mathrm{pH}=7.0$, (a) Iodoform, (b) MIAA, (c) DIAA, (d) TIAA. 


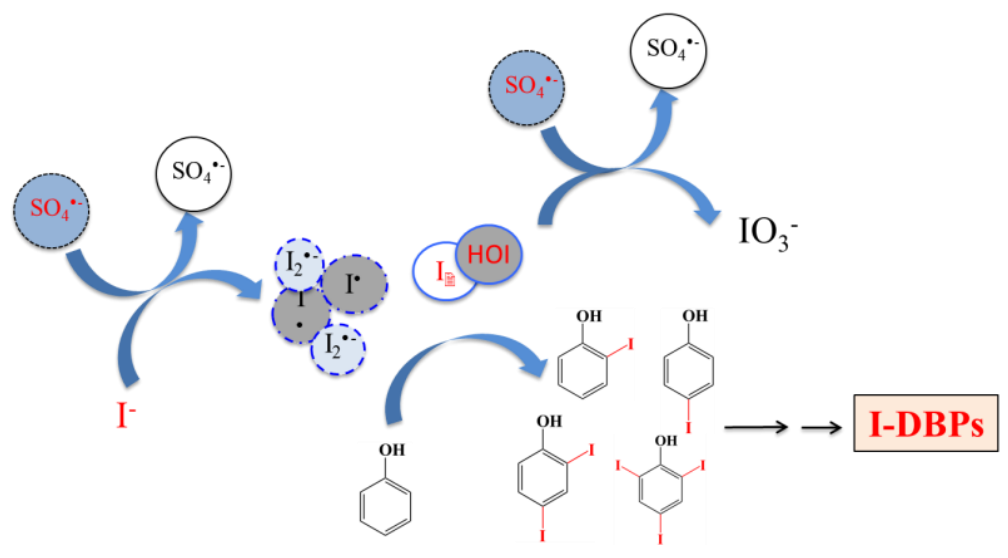

Fig. 6. Proposed transformation scheme of iodide in $\mathrm{SO}_{4}{ }^{-}$mediated reaction processes. 


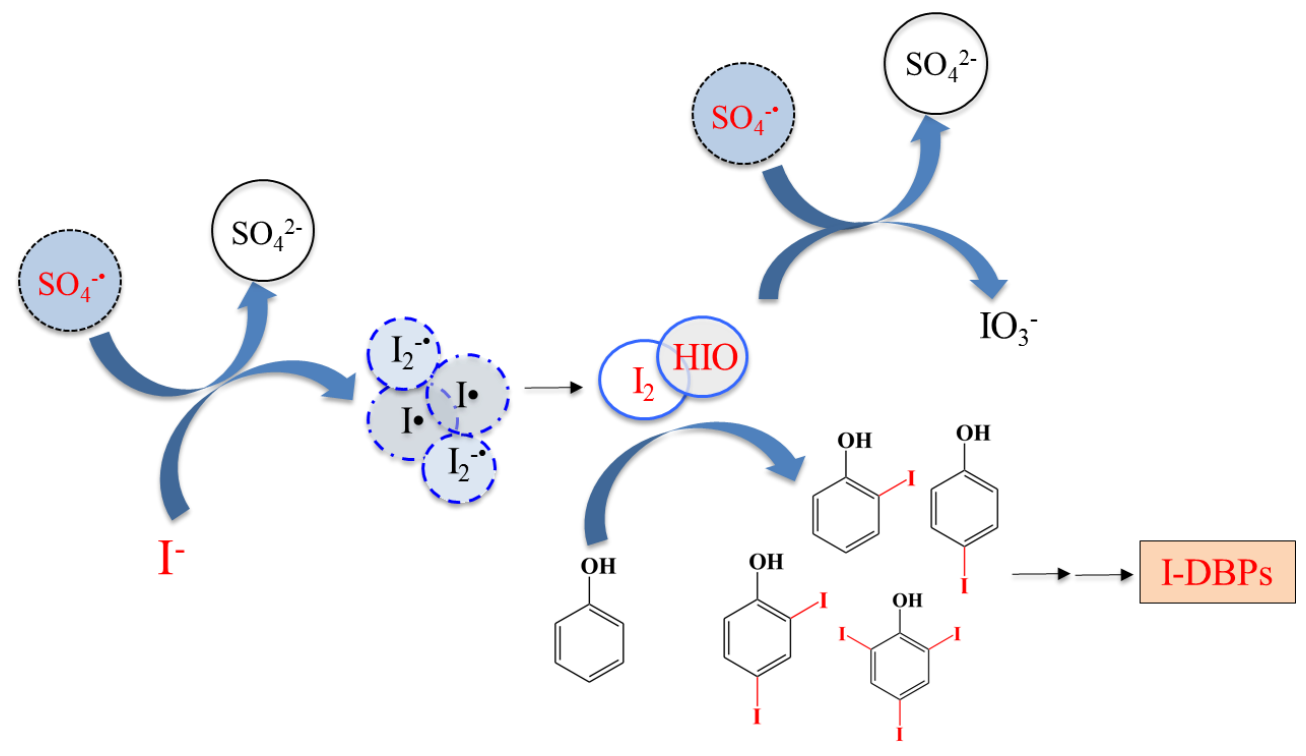

